\title{
Sinonasal aneurysmal bone cyst mimicking hemangioma
}

\author{
Shweta Shivakumar ${ }^{1}$, Shashikant Mhashal' ${ }^{1}$, Neeraj Shetty ${ }^{1}$, Ninad Subhash Gaikwad ${ }^{2}$ and Vivek Dokania ${ }^{*^{*}}$ (D)
}

\begin{abstract}
Background: Aneurysmal bone cyst $(A B C)$ is a benign, expansile bony lesion, primarily found in long bones. It is uncommon in facial bones and exceptionally rare in the sphenoethmoid sinus.

Case presentation: A 28-year-old male presented with complaints of bilateral nasal block and recurrent epistaxis. Rhinoscopy examination showed a lobulated lesion in the bilateral posterior nasal cavity and nasopharynx. A nasopharyngeal angiofibroma was suspected on radiological assessment. Pre-operative incisional biopsy revealed the tumor as hemangioma. With a probable diagnosis of hemangioma, the lesion was explored under general anesthesia. An endoscopic endonasal excision of a tumor mass attached to the sphenoid skull base was undertaken. Histopathological examination of the resected tissue confirmed the diagnosis of an aneurysmal bone cyst.

Conclusion: $A B C$ should be considered a rare differential for a hemorrhagic sinonasal mass in a young adult. Histopathological examination of the excised tissue is mandatory for a confirmatory diagnosis. Radiologic assessment and pre-operative incisional biopsy are essential from the diagnostic point of view; however, they can often cause a diagnostic dilemma with other vascular tumors such as nasopharyngeal angiofibroma or hemangioma.
\end{abstract}

Keywords: Aneurysmal bone cyst, Sphenoid sinus, Posterior ethmoid sinus, Blood-filled lesion

\section{Background}

$\mathrm{ABC}$ is a rare expansible, blood-filled bone lesion, first described by Jaffe and Lichtenstein in 1942. The pathophysiology of $A B C$ is not well understood. $A B C$ typically involves the long bones of the extremities, membranous bones of the thorax and pelvis, or vertebrae. The midline of the skull base and paranasal sinuses is not a common site for ABC. Only $2 \%$ of all aneurysmal bone cysts (ABCs) are found in the head and neck area, with the mandible and maxilla being the most frequent sites involved. The involvement of sphenoethmoid bone is extremely rare [1-4].

Although $\mathrm{ABC}$ is a non-neoplastic condition, its potential for rapid growth, considerable bony destruction, and

\footnotetext{
*Correspondence: drvivekdokania@gmail.com

1 Department of Otolaryngology- Head \& Neck Surgery, HBT Medical College and Dr RN Cooper Municipal General Hospital, Maharashtra 400056 Juhu, Mumbai, India

Full list of author information is available at the end of the article
}

extension into adjacent structures warrant early intervention [5]. $\mathrm{ABC}$ affects females more than males (female: male ratio of 2:1) [6]. The rarity of this disease in the head and neck region and a propensity to mimic vascular tumor makes this lesion more challenging for the head and neck surgeons. It is mainly found in the young age group ranging from 11 months to 20 years old. This article reports a 28-year-old male with $\mathrm{ABC}$ arising from the sphenoid sinus roof and extending into the sinonasal site.

\section{Case presentation}

A 28-year-old male presented with a history of intermittent epistaxis and bilateral progressive nasal obstruction for the past six months. He has a history of accidental nasal trauma with a metallic rod two years back. He was otherwise healthy and reported no history of tobacco or recreational drug abuse. No genetic or syndromic abnormalities were reported within his family. Flexible nasal endoscopy revealed a lobulated yellowish-pinkish mass, predominantly occluding the 
posterior left nasal cavity and nasopharynx, extending anteriorly up to the anterior end of the middle turbinate, causing right septal deviation anteriorly. The computed tomography scan (CT) of the brain and paranasal sinuses demonstrated an expansile soft tissue density polypoidal mass lesion in the left nasal cavity, superiorly extending to involve bilateral posterior ethmoid air cells, posteriorly extending to sphenoid sinus and nasopharynx. There was associated bony remodeling, as well relatively slight bony resorption of the sinus boundaries. Magnetic resonance imaging (MRI) showed a large lobulated heterogeneous posterior nasopharyngeal lesion isointense on T1-weighted images, variable hyperintense signal on $\mathrm{T} 2$ images and heterogeneous enhancement on post-contrast T1-weighted sequence. The lesion extended into the bilateral sphenoid sinus, left nasal cavity, bilateral ethmoids and anterior clival regions, with mild indentation over the left optic nerve and pituitary gland but without any invasion (Fig. 1). A probable diagnosis of nasopharyngeal angiofibroma was considered based on imaging findings.

A pre-operative biopsy was performed and concluded hemangioma. Diagnostic cerebral angiography of selective left external carotid artery showed mild abnormal vascular blush in the left upper nasal cavity in late arterial phase, suggestive of venous malformation/hemangioma. With a probable diagnosis of hemangioma or nasopharyngeal angioma, the patient was operated under general anesthesia through an endoscopic approach. A lobulated mass, firm to hard in consistency filling the nasopharynx and bilateral posterior nasal cavity with superior attachment to roof of sphenoid sinus and medially to the posterior end of nasal septum, was resected after ligating the left sphenopalatine artery. The sphenoidal skull base was seen to be completely thinned out. There was no CSF leak. Bilateral anterior nasal packing was done and the post-operative period was uneventful.

The histopathological examination of the resected tissue showed multiple dilated vascular spaces without any endothelial lining and separated by fibrous septae consisting of fibroblast and admixed with scattered osteoclasts like giant cells and siderophages. The loose fibrous stroma consisted of multiple capillaries, chronic inflammatory infiltrate and reactive woven bone. Foci of preserved overlying respiratory epithelium were also found (Fig. 2). Based on these features a confirmatory diagnosis of sinonasal $A B C$ was made. The patient has been regularly followed up for the last three months; post-operative endoscopic examination did not show any features of residual disease.

\section{Discussion}

Jaffe and Lichtenstein first described $\mathrm{ABCs}$ as benign, expansile, and lytic lesions of bone, pathologically consisting of thin-walled blood-filled cavities and lacking normal endothelium and vascular lamina. Their etiology is still not clear. They are presumed to be caused by primary processes leading to local hemodynamic alteration leading to venous obstruction or arteriovenous fistula with bone resorption or secondary causes such as trauma leading to hemorrhage [1, 2, 7-9]. Additionally, the secondary origin of $\mathrm{ABC}$ in a background of a preexisting lesion such as giant cell tumor, fibrous dysplasia, osteoblastoma, osteosarcoma, chondroblastoma, chondromyxoid fibroma, unicameral bone cyst has also been reported $[1,2]$. Clinically, presentation depends on the location. The lesions often produce symptoms due to

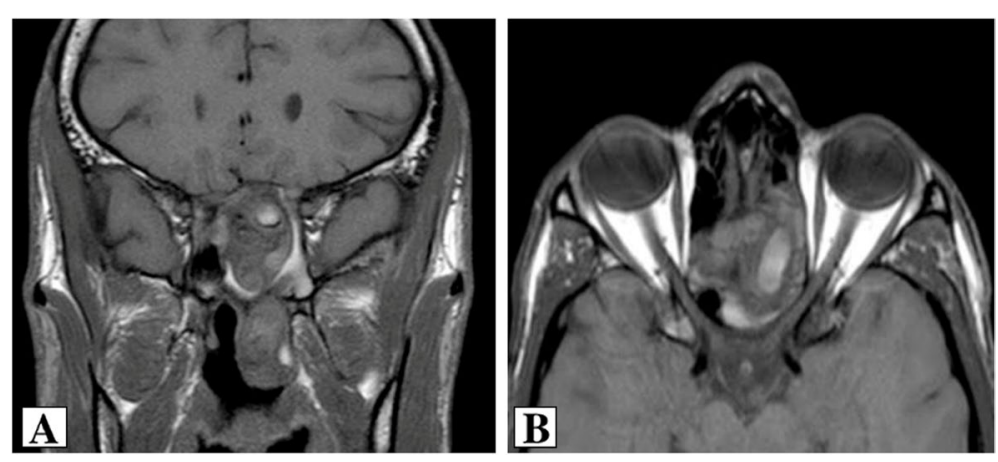

Fig. 1 T1- weighted post-contrast MRI showing the lesion of interest. A Coronal image showing a multiloculated, isointense to hyperintense lesion in the nasopharynx and sphenoid sinus causing slight indentation and erosion of sphenoid skull base. B Axial image shows the lesion involving bilateral ethmoid sinus and causing slight indentation over left optic nerve. 


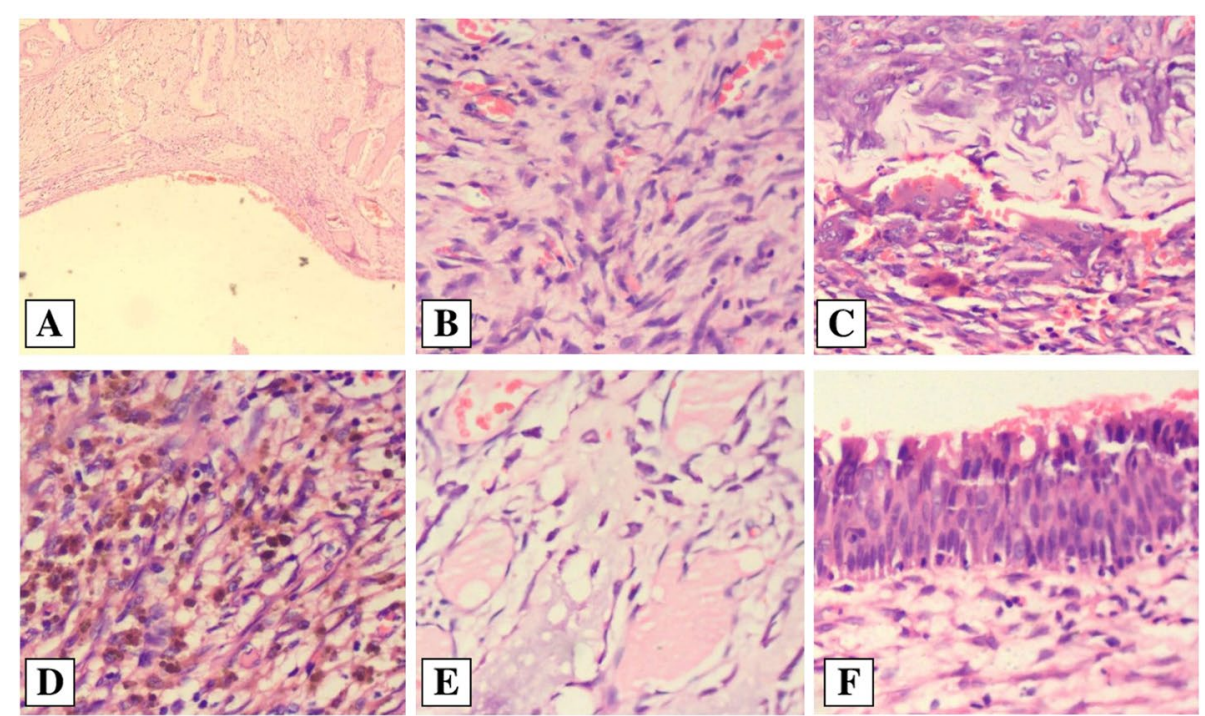

Fig. 2 Histopathological examination findings. A Dilated vascular spaces without endothelial lining. B Fibroblastic stroma consisting of plump fibroblast and multiple capillaries. C Scattered osteoclasts-like giant cells noted in stroma. D Siderophages in stroma. E Reactive woven bone in stroma. F Respiratory epithelium. (Hematoxylin \& eosin staining; 400X).

compression of adjacent structures or as a result of pathological fracture, rather than by themselves [7]. The skull base lesion mostly leads to focal neurological deficit [6].

Various authors have studied aneurysmal bone in the head and neck region. Kaffe et al., in their study involving $\mathrm{ABCs}$ of the jaw, found no difference in sex distribution [10]. They found maxillary and mandible involvement in the ratio of 1:2.4. Hady et al. reported a case of an aneurysmal bone cyst and claimed it to be the first reported case of aneurysmal bone cyst in the maxilla [11]. Radiology plays an instrumental role in the diagnosis of $\mathrm{ABC}$. A lobulated or multiloculated lesion with fluid level and a thin low signal rim is suggestive of $A B C$, noted on MRI and CT scans [12]. In CT scan, ABCs are typically lytic, expansile lesions with a thin cortical rim, partially eroded at places. Certain MRI features are characteristic but not pathognomonic of $\mathrm{ABC}$ and include endocavity fluid levels, endocardial hemorrhages, and peripheral fibrous orbit separating the lesion from the adjacent structure [6]. Although radiology plays an important role in diagnosing $\mathrm{ABC}$, it can cause a diagnostic dilemma with other highly vascularized tumors like angioma, giant cell tumor, osteoblastoma, chondroblastoma, telangiectatic osteosarcoma and traumatized bone cyst. Pre-operative angiography highlights the vascular supply of the tumor and aids in embolization planning. Histopathological examination is fundamental for a confirmatory diagnosis. Microscopic findings include multiple blood-filled spaces lined by fibrous septae containing loose fibroblastic stroma consisting of plump fibroblasts admixed with scattered osteoclasts like giant cells and siderophages. The stroma is generally rich in capillaries and can have chronic inflammatory infiltrate and reactive woven bone [13]. The histological differential of $A B C$ includes giant cell tumor, cavernous hemangioma, ossifying hematoma and fibrous dysplasia; multiple giant cells are present in all of the above [6]. Complete surgical excision is the treatment of choice, and it ranges from conservative surgery like curettage, enucleation and endoscopic surgery to a more aggressive intervention like paralateral rhinotomy and bifrontal craniotomy for sphenoethmoid $A B C$. Selective arterial embolization in large lesions may help to improve the results of surgery. Other management options such as interferon alpha- $2 \mathrm{a}$ and radiation therapies are reserved for unresectable lesions. An underlying lesion should be sought for in cases refractory to treatment $[1,4,14]$. Post-operative follow-up is recommended in the first two years since the recurrence rate tends to be high during this period. A recurrence rate of about $10-30 \%$ is reported with surgical excision, while a $50 \%$ recurrence rate is found with simple curettage $[15,16]$.

\section{Conclusion}

$\mathrm{ABC}$ is a rare tumor in the sphenoethmoid sinus and should be considered in the differential for hemorrhagic sinonasal mass. In spite of known characteristic radiological features for $\mathrm{ABC}$, they can still be confused with other vascular tumors like hemangioma and nasopharyngeal angioma. Therefore, histopathological examination 
is always mandated and considered the gold standard for confirmatory diagnosis; imaging can cause diagnosis dilemma and hence should not be considered pathognomonic for $\mathrm{ABC}$.

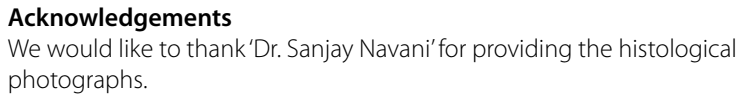

\section{Authors' contributions}

SS assisted in surgery, evaluated the clinical findings and contributed to the manuscript, SM performed the surgery and contributed to the manuscript, NS performed the surgery and contributed to the manuscript, NSG contributed to the manuscript and proofread final manuscript, and VD contributed to the manuscript and proofread final manuscript. The authors read and approved the final manuscript.

\section{Funding}

None

\section{Availability of data and material}

Not applicable

\section{Declarations}

Ethics approval and consent to participate

Not applicable

\section{Consent for publication}

Verbal and written consent for publication was obtained from the patient

\section{Competing interests}

The authors declare that they have no competing interests.

\section{Author details}

'Department of Otolaryngology- Head \& Neck Surgery, HBT Medical College and Dr RN Cooper Municipal General Hospital, Maharashtra 400056 Juhu, Mumbai, India. ${ }^{2}$ Professor and Head, Department of Otolaryngology- Head \& Neck Surgery, HBT Medical College and Dr RN Cooper Municipal General Hospital, Maharashtra 400056 Juhu, Mumbai, India.

Received: 21 September 2021 Accepted: 7 January 2022

Published online: 28 January 2022

\section{References}

1. Guilemany JM, Alobid I, Blanch JL, Ballesteros F, Alós L, Mullol J (2004) Orbitoethmoid aneurysmal bone cyst. Case report and literature review Rhinology 42(3):164-166

2. Ruiz de la Cuesta F, Alenda C, Monerris E, Gras Albert JR (2007) Quiste óseo aneurismático de etmoides: a propósito de un caso y revisión de la literatura médica [Aneurysmal bone cyst of the ethmoid: apropos of a case and review of the medical literature]. Acta Otorrinolaringol Esp 58(3):113-115

3. Vergel De Dios AM, Bond JR, De Dios Vergel, McLeod RA, Unni KK (1992) Aneurysmal bone cystAneurysmal bone cyst A clinicopathologic study of 238 cases. Cancer 69(12):2921-2931 (https://doi.org/10.1002/10970142(19920615)69:12<2921::aid-cncr2820691210>3.0.co;2-e)

4. Hrishikesh KA, Narlawar RS, Deasi SB, Aniruddha K, Maheshwari S (2002) Case report: Aneurysmal bone cyst of the ethmoid bone. Br J Radiol 75(899):916-918. https://doi.org/10.1259/bjr.75.899.750916

5. Resnick D (1995) Aneurysmal bone cyst. Diagnosis of bone and joint disorders (3rd ed). Philadelphia, PA: WB saunders 6: 3866-78.

6. Serra A, Gulino A, Di Luca M, Conti A, Maniaci A, Campione G et al (2017) Sinonasalaneurysmal bone cyst: article review. Acta Med Mediterr 33(5):869-873
7. Munk PL, Helms CA, Holt RG, Johnston J, Steinbach L, Neumann C (1989) MR imaging of aneurysmal bone cysts. AJR Am J Roentgenol 153(1):99101. https://doi.org/10.2214/ajr.153.1.99

8. Hudson TM (1984) Fluid levels in aneurysmal bone cysts: a CT feature. AJR Am J Roentgenol 142(5):1001-1004. https://doi.org/10.2214/ajr.142.5. 1001

9. Carlson DH, Wilkinson RH, Bhakkaviziam A (1972) Aneurysmal bone cyst in children. AJR 116(3):644-650

10. Kaffe I, Naor H, Calderon s, Buchner A (1999) Radiological and clinical features of aneurysmal bone cyst of the jaws. Dentomaxillofac Radiol 28(3):167-172. https://doi.org/10.1038/sj/dmfr/4600434

11. Hady MR, Ghanaam B, Hady MZ (1990) Aneurysmal bone cyst of the maxillary sinus. J Laryngol Otol 104(6):501-503. https://doi.org/10.1017/ s0022215100113003

12. Sinha NR, Szmigielski W, Khanna M (2010) Aneurysmal bone cyst of the ethmoid sinus: A case report. Pol J Radiol 75(3):65-67

13. Saito K, Fukuta K, Takahashi M, Seki Y, Yoshida J (1998) Benign fibroosseous lesions involving the skull base, paranasal sinuses, and nasal cavity. Report of two cases J Neurosurg 88(6):1116-1119. https://doi.org/10. 3171/jns.1998.88.6.1116

14. Segall L, Cohen-Kerem R, Ngan BY, Forte V (2008) Aneurysmal bone cysts of the head and neck in pediatric patients: a case series. Int J Pediatr Otorhinolaryngol 72(7):977-983. https://doi.org/10.1016/j.jporl.2008.02. 021

15. Hashemi SM, Heidarpour M, Eshaghian A, Ansari P, Hashemi MS, Yaghoobi M, Barati S (2015) A rare case of aneurysmal bone cyst in the paranasal sinus. Iran J Otorhinolaryngol 27(82):395

16. H Ismail-Koch VD, Jonas N, Malone M, Chong W, Jephson C (2012) Aneurysmal bone cyst of the anterior ethmoid: management of this rare entity. Internet J Otorhinolaryngol 14(2)

\section{Publisher's Note}

Springer Nature remains neutral with regard to jurisdictional claims in published maps and institutional affiliations.

\section{Submit your manuscript to a SpringerOpen ${ }^{\circ}$ journal and benefit from:}

- Convenient online submission

- Rigorous peer review

- Open access: articles freely available online

- High visibility within the field

- Retaining the copyright to your article

Submit your next manuscript at $\boldsymbol{\nabla}$ springeropen.com 